\title{
DOES THE IMPLEMENTATION OF SMOKE-FREE LAWS AND SMOKING CULTURE AFFECT EXPOSURE TO TOBACCO SMOKING? RESULTS FROM 3 HOSPITALITY SETTINGS IN SOUTH KOREA
}

\author{
MYUNG-BAE PARK 1 , TAE SIC LEE ${ }^{2}$, JEE EUN OH ${ }^{3}$, and DO HOON LEE \\ ${ }^{1}$ Pai Chai University, Daejeon, Republic of Korea \\ Department of Gerontology Health and Welfare \\ ${ }^{2}$ Yonsei University Wonju College of Medicine, Wonju, Republic of Korea \\ Department of Family Medicine \\ ${ }^{3}$ National Cancer Center, Goyang, Republic of Korea \\ Department of Laboratory Medicine
}

\begin{abstract}
Objectives: It is especially difficult for hospitality workers to avoid secondhand smoke (SHS), meaning that they are likely particularly vulnerable to the effects of SHS. The authors aimed to determine the degree to which smoke-free laws protect hospitality workers from SHS exposure, by examining biochemical markers of such exposure. Material and Methods: This was a cross-sectional study examining SHS exposure in non-smoking employees working in hospitality settings where smoking is prohibited or permitted. The following biomarkers were selected: cotinine and tobaccospecific nitrosamines, which are known to measure SHS exposure, and 2 representative carcinogens: 4-(methylnitrosamino)-1-(3-pyridyl)-1-butanol and 4-(methylnitrosamino)-1-(3-pyridyl)-1-butanone (NNK). The authors compared these biomarkers between 3 hospitality settings. A descriptive analysis was performed. In addition, they conducted 1-way and 2-way analysis of covariance (ANCOVA) to compare the biochemical markers. Results: Smoking substances were identified by smoking ban levels. In the case of hair nicotine and urine cotinine, their concentrations were lower in areas with a complete smoking ban than in both areas with a separate smoking room and no smoking ban; however, there was no statistically significant difference between these. In the case of dust NNK, its level was the lowest in areas with a complete smoking ban. To confirm the smoking ban effect by hospitality settings, the authors checked the results of the 2-way ANCOVA. In karaoke and billiard halls, the dust NNK concentrations were significantly higher in areas with no smoking ban than in areas with a separate smoking room. Conclusions: Exposure to SHS is more prevalent in places that are more lenient when it comes to smoking (e.g., Internet cafés) than in places that are not (e.g., restaurants and cafés), even when smoking is similarly prohibited in both types of places. Int J Occup Med Environ Health. 2021;34(1):53-67
\end{abstract}

Key words:

secondhand smoke, smoking ban, smoke-free, workplace, tobacco-specific nitrosamines, tobacco control

Funding: this work was supported by the National Research Foundation of Korea (NRF) (project NRF-2017R1C1B5017638, entitled "Young Researcher Program," project manager: Myung-Bae Park).

Received: October 8, 2019. Accepted: August 17, 2020.

Corresponding author: Do Hoon Lee, National Cancer Center, Department of Laboratory Medicine, 323 Ilsan-ro, Ilsandong-gu, Goyang-si Gyeonggi-do, 10408, Goyang, Republic of Korea (e-mail: dhlee@ncc.re.kr). 


\section{INTRODUCTION}

\section{Secondhand smoke and health issues}

Secondhand smoke (SHS) is as harmful to health as is active smoking. For non-smokers, SHS exposure can harm the respiratory system and cause diseases such as lung cancer and chronic obstructive pulmonary disease, along with breast, cervical, and bladder cancer. It also causes cardiovascular disease and can irreparably harm fetal health [1]. Nowadays, SHS exposure imposes one of the most severe disease burdens globally [2], killing approx. 900000 individuals annually [3].

More specifically, SHS refers to a passive or involuntary inhalation of cigarette smoke by a non-smoker. Harmful substances, such as carbon monoxide, nicotine, polycyclic aromatic hydrocarbons, and particulate matter, are generated due to combustion of cigarettes or vaporization of electronic cigarettes. These substances are present in the air and are inhaled by non-smokers, which adversely affects their body. Previous studies have shown that if smoking is not restricted, particulate matter and nicotine concentrations increase, resulting in poorer air quality [4]. Therefore, in order to prevent SHS, it is necessary to improve the air quality deteriorated by smoking, and protecting non-smokers from cigarette smoke may be the most basic way. Smoke-free laws (SFLs) reduce smoking-related mortality [5], and Coughlin's study [4] found that the incidence of cardiovascular and respiratory diseases decreased after implementing SFLs. It is also known that smoking ban at workplaces and public places can reduce the incidence of acute myocardial infarction by about $20 \%$ [6].

\section{Global efforts to reduce SHS}

To reduce the health threats of SHS, the World Health Organization (WHO) has stipulated (in Article 8 of the Framework Convention on Tobacco Control [FCTC]) that governments should endeavor to protect people from tobacco smoke exposure in "workplaces, public transport, indoor public places and, as appropriate, other public places" [7]. Reports of 2007 indicated that $>200$ million people were protected by $100 \%$ SFLs in public places [8]; on the other hand, this implies that most people remain unprotected by SFLs.

As of 2016, one-fifth of men and one-third of women were globally exposed to SHS [3]. Naturally, the degree to which a person is exposed to SHS varies according to regional or national smoking laws/regulations, or the lack thereof. Governments worldwide are continually striving to prevent SHS exposure. While the USA has no federal laws prohibiting smoking, various states have implemented regulations to that effect; Arizona was the first state to restrict smoking in some public places (in 1973), while Minnesota was the first state to prohibit smoking in public places altogether (in 1975). Minnesota's law was later reinforced by the Freedom to Breathe Act in 2007 [9]. In 1995, California became the first state to enact a statewide smoking ban, which was later introduced in Alaska in July 2018. By June 2016, 28 states had comprehensively restricted smoking indoors, with an estimated $81.5 \%$ of people residing in the USA being legally protected from tobacco smoke exposure in public places (e.g., workplaces, restaurants) [10]. Similarly, in 2007, Germany passed a federal non-smoking act designating all public places (e.g., restaurants, bars, public transport) as smoke-free [11]. The United Kingdom also implemented SFLs in all regions (with Scotland in 2006 and England in 2007) [12]. As is evident, SFLs pursuant to the WHO FCTC are now widespread globally.

\section{Smoke-free zones in South Korea}

South Korea has successfully enforced and improved its SFLs since the enactment of the National Health Promotion Act (NHPA) in 1995. The scope of public smokefree zones has continually broadened since enactment; schools became smoke-free in 1999, followed by public bathhouses, Internet cafés, and restaurants of $\geq 150 \mathrm{~m}^{2}$ 
in 2003; all restaurants in 2015; and billiard halls in 2017. Under NHPA, medical clinics, hospitals, schools, other child-related facilities, and various indoor and outdoor areas are designated as smoke-free areas.

At the time of enactment, smoking was allowed in cafés and restaurants that were $\leq 150 \mathrm{~m}^{2}$ in area. Internet cafés also had designated smoking zones on their premises. In June 2013 and January 2015, all indoor areas in Internet cafés, and all cafés and restaurants, respectively, were designated as smoke-free zones. This prompted many Internet cafés to set up rooms that would completely separate smokers from non-smokers, and to install necessary devices to prevent the spread of smoke; alternatively, smokers had to go to the rooftop or outside to smoke. People caught smoking in smokefree zones are fined KRW 100000 (USD 80), while the owners of facilities designated as a smoke-free zones are fined KRW 5000000 (USD 40 000) or less if they violate the relevant provisions (e.g., providing ashtrays, making an indoor smoking area).

In this study, the authors further separated Internet cafés from restaurants and cafés because smokers are unlikely to go outside while playing games in the former café type, so smoking is likely more frequent in such cafés despite their being smoke-free zones [13]. Indeed, crackdowns on smoking cessation violations in Internet cafés are overwhelmingly high [14]. Experts, however, have claimed that South Korea's smoking ban has not been as effective as expected, and that the no-smoking policy largely relies on promotional activities. Furthermore, smokers often breach the smoke-free policies in certain areas (e.g., Internet cafés) [15]. Thus, while SFLs are the most powerful means of preventing SHS exposure, their presence does not guarantee full protection. Globally, smoking bans are also imposed only on a limited range of indoor spaces (e.g., hospitals, public institutions), and even when SFLs are in place, they are not fully enforced [15]. Thus, large numbers of people remain exposed to SHS in areas covered by SFLs. It is especially difficult for hospitality workers to avoid SHS, meaning that they are likely particularly vulnerable to the effects of SHS. If there is no system to protect them from SHS, or if it does not operate, it will be an essential health problem for them.

\section{Aims and goals}

The authors aimed to determine the degree to which SFLs protect hospitality workers from SHS exposure, by examining biochemical markers of that exposure. Specifically, they examined:

- indoor places where smoking is banned by law and where good compliance with the no-smoking policy is expected,

- smoke-free zones where compliance with the SFL is unlikely,

- places where smoking is not banned by law.

\section{MATERIAL AND METHODS}

\section{Study design}

This was a cross-sectional study examining SHS exposure in non-smoking employees working in hospitality settings where smoking is prohibited or permitted. The authors compared the biomarkers of SHS exposure between the following areas:

- cafés and restaurants where smoking is completely banned indoors,

- Internet cafés where smoking is banned but where the ban is not enforced,

- karaoke and billiard halls, where smoking is allowed.

As part of an additional analysis, they also divided smokefree zones as follows:

- areas with a complete smoking ban (smoking is prohibited in any indoor space);

- areas equipped with a separate indoor smoking room (hereinafter: "separated areas");

- areas with no smoking ban. 


\section{Participants}

The survey participants were recruited through social networks, local business associations, and snowballing methods such as referrals and individual solicitations. For the participants to be eligible, it was required that they had worked at a restaurant, a café, a karaoke hall, a billiard hall, or an Internet café for at least 2 months, and had never smoked or were not smoking at the time of the survey. Only 1 participant per business was allowed. The participants were compensated for the study with KRW 60000 (USD 50).

\section{Measurements}

Environmental and biological markers were evaluated to determine the participants' SHS exposure in their workplace. The authors also administered a questionnaire asking about the facilities and participants themselves. The questionnaires were administered by a surveyor via face-to-face interviews at the participants' workplaces. Urine samples were collected by the participants in Korea in August-September 2017, and then given to the surveyor.

\section{Questionnaire}

For the facility characteristics, the authors evaluated whether or not the participants could smoke on the premises, the number of ventilators, and if a ventilator was present, whether it always functioned during business hours. As for the participant characteristics, the authors evaluated the smoking history, working hours, and the perceived SHS exposure at the workplace and home. They evaluated exposure at the workplace with the following question: "Have you been exposed to tobacco smoke from other people in your workplace during last week?" while exposure at home was evaluated with the following question: "Have you been exposed to tobacco smoke from other people at your home during the last week?".

\section{Hair nicotine}

Hair nicotine is suitable for evaluating long-term exposure to SHS (around 2-3 months) [16]. People with gray and dyed hair were excluded. To evaluate hair nicotine (which reflected nicotine exposure in the past 2-3 months), samples that included roots and about $2 \mathrm{~cm}$ of hair were collected. The surveyor directly pulled it out wearing latex gloves.

Urine cotinine and 4-(methylnitrosamino)-1-(3-pyridyl)-1-butanol Urine cotinine and 4-(methylnitrosamino)-1-(3-pyridyl)1-butanol (NNAL) are excellent indicators of smoking exposure. Cotinine exposure can be assessed within a 2-day period and NNAL within up to a month [16]. To measure these markers, over $20 \mathrm{ml}$ of urine was collected from each participant, which was then refrigerated using a freezer pack and an icebox, and stored in a $-70^{\circ} \mathrm{C}$ deep freezer. Adjustments were also made for creatinine at the time of statistical analysis.

\section{Dust 4-(methylnitrosamino)-1-(3-pyridyl)-1-butanone} Nicotine reacts with air to produce 4-(methylnitrosamino)1-(3-pyridyl)-1-butanone (NNK), a tobacco-specific nitrosamine and carcinogen [24]. Dust was collected by wiping the cotton filter soaked in methanol. It was collected from the inside of a ventilator that sent indoor air outside of the workplace. The filter was enclosed in a plastic zipper bag to prevent loss or damage of the dust, and then stored and transported.

\section{Statistical analysis}

A descriptive analysis was performed for the facility and participant characteristics. In addition, a correlation analysis was performed to confirm that the substances were related. Then, a 1-way analysis of covariance (ANCOVA) was conducted to compare the biochemical markers, after adjusting for the participants' perceived SHS exposure at their home. Log-transformation was then conducted to reflect the skewness of the biochemical markers; thus, geometric mean (GM) and median (Me) values were used [17]. In addition, a 2-way ANCOVA was implemented to iden- 
tify the effect of designating non-smoking zones by workplaces; however, the collected sample was insufficient for this analysis. Therefore, the statistical analysis was resampled 1000 times using the bootstrapping technique which makes it possible to analyze non-parametric data without assuming a probability distribution, which is particularly useful in medical research with small sample sizes [18]. The bootstrapping is often used to perform a multivariate analysis or to interact with small samples [19].

\section{RESULTS}

\section{Facility and participant characteristics}

Of the 68 facilities studied, 20 were restaurants and cafés, 32 were karaoke and billiard halls, and 16 were Internet cafés. The median number of ventilators in these restaurants and cafés was 2 . Around $60 \%$ of these facilities operated ventilators full-time during business hours unless dictated otherwise by special circumstances, while $40 \%$ did not have any ventilators or did not operate them. Seventy-five percent of the restaurants and cafés had a complete smoking ban, and $35 \%$ of restaurant workers said that they had been exposed to SHS in their workplace. Karaoke and billiard halls had a median of 6 ventilators, and almost all of these facilities operated the ventilators during business hours $(96.9 \%)$. In more than half of these areas (56.3\%), smoking was permitted without restrictions, whereas $9.4 \%$ had a complete smoking ban. Internet cafés were equipped with a median of 2 ventilators, and $93.8 \%$ operated these ventilators full-time during business hours. All Internet cafés reported having separate smoking rooms, and $75.0 \%$ reported exposure to SHS.

There was a high percentage of women across all categories. The average age of the respondents working in restaurants and cafés was 23 years, in karaoke and billiard halls 43 years, and in Internet cafés 22 years. Of the participants working in karaoke and billiard halls, $90.6 \%$ had been exposed to SHS at their workplace (Table 1).

\section{Correlation analysis}

Pearson's correlation analysis of the 4 biochemical markers of SHS exposure was conducted. All the 4 markers were positively correlated with one another $(\mathrm{r}=0.263-0.434$, $\mathrm{p}<0.05$ ), suggesting their validity (Table 2 ).

\section{Biochemical marker levels}

By workplace

On the one hand, the hair nicotine concentration was the highest among Internet café workers $(\mathrm{GM}=1.67 \mathrm{ng} / \mathrm{mg}$, $\mathrm{Me}=1.89 \mathrm{ng} / \mathrm{ml})$, followed by karaoke and billiard hall workers $(\mathrm{GM}=1.61 \mathrm{ng} / \mathrm{ml}, \mathrm{Me}=1.23 \mathrm{ng} / \mathrm{ml})$, and restaurant and café workers $(\mathrm{GM}=0.54 \mathrm{ng} / \mathrm{ml}, \mathrm{Me}=0.47 \mathrm{ng} / \mathrm{ml})$ (Table 3).

Urine cotinine, on the other hand, was the highest among karaoke and billiard hall workers $(\mathrm{GM}=11.64 \mathrm{ng} / \mathrm{ml}$, $\mathrm{Me}=9.21 \mathrm{ng} / \mathrm{ml}$ ), followed by Internet café workers $(\mathrm{GM}=5.19 \mathrm{ng} / \mathrm{ml}, \mathrm{Me}=6.13 \mathrm{ng} / \mathrm{ml})$, and restaurant and café workers $(\mathrm{GM}=2.62 \mathrm{ng} / \mathrm{ml}, \mathrm{Me}=3.88 \mathrm{ng} / \mathrm{ml})$.

Urine NNAL was the highest in karaoke and billiard hall workers $(\mathrm{GM}=2.38 \mathrm{pg} / \mathrm{ml}, \mathrm{Me}=2.26 \mathrm{pg} / \mathrm{ml})$, followed by restaurant and café workers $(\mathrm{GM}=1.78 \mathrm{pg} / \mathrm{ml}, \mathrm{Me}=$ $1.67 \mathrm{pg} / \mathrm{ml})$, and Internet café workers (GM $=1.77 \mathrm{pg} / \mathrm{ml}$, $\mathrm{Me}=1.71 \mathrm{pg} / \mathrm{ml}$ ). When using the median as the reference, Internet café workers showed higher levels than restaurant and café workers.

Dust NNK was found to be the highest in Internet cafés $(\mathrm{GM}=1268.50 \mathrm{pg} / \mathrm{mg}, \mathrm{Me}=1407.88 \mathrm{pg} / \mathrm{mg})$, followed by karaoke and billiard halls ( $\mathrm{GM}=$ $709.31 \mathrm{pg} / \mathrm{mg}, \mathrm{Me}=1160.00 \mathrm{pg} / \mathrm{mg}$ ), and restaurants and cafés $(\mathrm{GM}=44.40 \mathrm{pg} / \mathrm{mg}$, Me $=55.44 \mathrm{pg} / \mathrm{mg})$. The results were the same when the bootstrapping method was employed (Table 3).

For hair nicotine, urine cotinine, and dust NNK, the above results were the same when the bootstrapping method was employed. However, for urine NNAL, the results differed slightly depending on the descriptive statistic used (GM or Me). As above, karaoke and billiard hall workers had the highest levels 
Table 1. Characteristics of 68 participants" who worked at restaurants and cafés, karaoke and billiard halls, and Internet cafés, involved in the study on examining secondhand smoke (SHS) exposure in non-smoking employees, Korea, August-September 2017

\begin{tabular}{|c|c|c|c|}
\hline \multirow[b]{2}{*}{ Variable } & \multicolumn{3}{|c|}{ Participants } \\
\hline & restaurant and café & $\begin{array}{c}\text { karaoke } \\
\text { and billiard hall }\end{array}$ & Internet café \\
\hline \multicolumn{4}{|l|}{$\operatorname{Sex}[\mathrm{n}(\%)]$} \\
\hline male & $4(20.0)$ & $9(28.1)$ & $7(43.8)$ \\
\hline female & $16(80.0)$ & $23(71.9)$ & $9(56.2)$ \\
\hline Age [years] (M (min.-max)) & $23(20-48)$ & $43(20-73)$ & $22(19-25)$ \\
\hline \multicolumn{4}{|l|}{ Workplace } \\
\hline facilities $[\mathrm{n}(\%)]$ & $20(29.4)$ & $32(47.1)$ & $16(23.5)$ \\
\hline \multicolumn{4}{|l|}{ mechanical ventilation } \\
\hline ventilators [n] (Me (IQR)) & $2(1-2)$ & $6(3.5-8)$ & $2(1.5-3)$ \\
\hline no ventilator or not operated $[\mathrm{n}(\%)]$ & $8(40.0)$ & $1(3.1)$ & $1(6.3)$ \\
\hline always operated during business hours [n (\%)] & $12(60.0)$ & $31(96.9)$ & $15(93.8)$ \\
\hline \multicolumn{4}{|l|}{ smoking policy $[\mathrm{n}(\%)]$} \\
\hline complete smoking ban & $18(75.0)$ & $3(9.4)$ & $0(0.0)$ \\
\hline smoking permitted in a separate smoking room & $2(25.0)$ & $11(34.4)$ & $16(100.0)$ \\
\hline smoking permitted anywhere & $0(0.0)$ & $18(56.3)$ & $0(0.0)$ \\
\hline \multicolumn{4}{|l|}{ Self-reported SHS exposure [n (\%)] } \\
\hline at the workplace & $7(35.0)$ & $29(90.6)$ & $12(75.0)$ \\
\hline at home & $4(20.0)$ & $2(6.25)$ & $1(6.25)$ \\
\hline
\end{tabular}

IQR - interquartile range.

"Participants were those who had worked at the facility for at least 2 months.

Table 2. Correlation analysis $(\mathrm{N}=68)$ in the study on examining secondhand smoke (SHS) exposure in non-smoking employees, Korea, August-September 2017

\begin{tabular}{lcccc}
\hline \multirow{2}{*}{ Variable } & \multicolumn{4}{c}{ Correlation } \\
\cline { 2 - 5 } & 1 & 2 & 3 & 4 \\
\hline 1. Hair nicotine & 1 & $0.263(\mathrm{p}=0.030)$ & $0.406(\mathrm{p}=0.001)$ & $0.410(\mathrm{p}=0.001)$ \\
2. Urine cotinine & $0.263(\mathrm{p}=0.030)$ & 1 & $0.434(\mathrm{p}<0.000)$ & $0.302(\mathrm{p}=0.012)$ \\
3. Urine NNAL & $0.406(\mathrm{p}=0.001)$ & $0.434(\mathrm{p}=0.001)$ & 1 & $0.281(\mathrm{p}=0.021)$ \\
4. Dust NNK & $0.410(\mathrm{p}=0.001)$ & $0.302(\mathrm{p}=0.012)$ & $0.281(\mathrm{p}=0.021)$ & 1 \\
\hline
\end{tabular}

NNAL - 4-(methylnitrosamino)-1-(3-pyridyl)-1-butanol; NNK - 4-(methylnitrosamino)-1-(3-pyridyl)-1-butanone. Log-transformed value.

$(\mathrm{GM}=2.40 \mathrm{pg} / \mathrm{ml}, \mathrm{Me}=2.33 \mathrm{pg} / \mathrm{ml})$, followed by restaurant and café workers $(\mathrm{GM}=1.81 \mathrm{pg} / \mathrm{ml}, \mathrm{Me}=1.70 \mathrm{pg} / \mathrm{ml})$, and Internet café workers $(\mathrm{GM}=1.79 \mathrm{pg} / \mathrm{ml}, \mathrm{Me}=1.77 \mathrm{pg} / \mathrm{ml})$.
When using the median, karaoke and billiard hall workers, as well as Internet café workers, had the highest levels, while the remaining 2 groups were similar in their level. 
Table 3. Concentrations of hair nicotine, urine cotinine, urine 4-(methylnitrosamino)-1-(3-pyridyl)-1-butanol (NNAL), and dust 4-(methylnitrosamino)-1-(3-pyridyl)-1-butanone (NNK) by facility, in the study on examining secondhand smoke (SHS) exposure in non-smoking employees, Korea, August-September 2017

\begin{tabular}{|c|c|c|c|c|c|c|}
\hline \multirow{3}{*}{ Substance } & \multicolumn{6}{|c|}{$\begin{array}{l}\text { Participants } \\
(\mathrm{N}=68)\end{array}$} \\
\hline & \multicolumn{2}{|c|}{ restaurant and café } & \multicolumn{2}{|c|}{ karaoke and billiard hall } & \multicolumn{2}{|c|}{ Internet café } \\
\hline & $\mathrm{N}=20$ & iterations $=1000$ & $\mathrm{~N}=32$ & iterations $=1000$ & $\mathrm{~N}=16$ & iterations $=1000$ \\
\hline \multicolumn{7}{|c|}{ Hair nicotine $[\mathrm{ng} / \mathrm{mg}]$} \\
\hline $\mathrm{GM}(95 \% \mathrm{Cl})$ & $\begin{array}{c}0.54 \\
(0.39-0.74)\end{array}$ & $\begin{array}{c}0.55 \\
(0.40-0.74)\end{array}$ & $\begin{array}{c}1.61 \\
(0.97-2.68)\end{array}$ & $\begin{array}{c}1.67 \\
(1.00-2.63)\end{array}$ & $\begin{array}{c}1.67 \\
(0.95-2.93)\end{array}$ & $\begin{array}{c}1.72 \\
(0.94-2.79)\end{array}$ \\
\hline $\mathrm{Me}(\mathrm{IQR})$ & $\begin{array}{c}0.47 \\
(0.31-0.88)\end{array}$ & $\begin{array}{c}0.46 \\
(0.32-1.13)\end{array}$ & $\begin{array}{c}1.23 \\
(0.51-4.73)\end{array}$ & $\begin{array}{c}1.24 \\
(0.51-4.59)\end{array}$ & $\begin{array}{c}1.89 \\
(1.22-2.85)\end{array}$ & $\begin{array}{c}1.81 \\
(1.14-2.63)\end{array}$ \\
\hline \multicolumn{7}{|c|}{ Urine cotinine $[\mathrm{ng} / \mathrm{mg}] \mathrm{Cr}$} \\
\hline GM $(95 \% \mathrm{Cl})$ & $\begin{array}{c}2.62 \\
(1.52-4.54)\end{array}$ & $\begin{array}{c}2.72 \\
(1.51-4.31)\end{array}$ & $\begin{array}{c}11.64 \\
(7.49-18.11)\end{array}$ & $\begin{array}{c}11.94 \\
(7.89-18.34)\end{array}$ & $\begin{array}{c}5.19 \\
(3.53-7.64)\end{array}$ & $\begin{array}{c}5.24 \\
(3.49-7.49)\end{array}$ \\
\hline $\mathrm{Me}(\mathrm{IQR})$ & $\begin{array}{c}3.88 \\
(1.16-7.45)\end{array}$ & $\begin{array}{c}4.54 \\
(1.17-7.40)\end{array}$ & $\begin{array}{c}9.21 \\
(5.01-26.45)\end{array}$ & $\begin{array}{c}9.76 \\
(4.64-30.10)\end{array}$ & $\begin{array}{c}6.13 \\
(2.88-9.30)\end{array}$ & $\begin{array}{c}5.68 \\
(2.77-7.58)\end{array}$ \\
\hline \multicolumn{7}{|c|}{ Urine NNAL $[\mathrm{pg} / \mathrm{mg}] \mathrm{Cr}$} \\
\hline $\mathrm{GM}(95 \% \mathrm{Cl})$ & $\begin{array}{c}1.78 \\
(1.23-2.56)\end{array}$ & $\begin{array}{c}1.81 \\
(1.27-2.65)\end{array}$ & $\begin{array}{c}2.38 \\
(1.80-3.14)\end{array}$ & $\begin{array}{c}2.40 \\
(1.84-3.14)\end{array}$ & $\begin{array}{c}1.77 \\
(1.32-2.38)\end{array}$ & $\begin{array}{c}1.79 \\
(1.29-2.35)\end{array}$ \\
\hline $\mathrm{Me}(\mathrm{IQR})$ & $\begin{array}{c}1.67 \\
(0.94-2.15)\end{array}$ & $\begin{array}{c}1.70 \\
(0.86-2.35)\end{array}$ & $\begin{array}{c}2.26 \\
(1.40-3.65)\end{array}$ & $\begin{array}{c}2.33 \\
(1.44-3.54)\end{array}$ & $\begin{array}{c}1.71 \\
(1.21-2.91)\end{array}$ & $\begin{array}{c}1.77 \\
(1.11-2.88)\end{array}$ \\
\hline \multicolumn{7}{|l|}{ Dust NNK [pg/mg] } \\
\hline $\mathrm{GM}(95 \% \mathrm{Cl})$ & $\begin{array}{c}44.40 \\
(29.08-67.78)\end{array}$ & $\begin{array}{c}45.09 \\
(28.43-66.08)\end{array}$ & $\begin{array}{c}709.31 \\
(368.4-1365.69)\end{array}$ & $\begin{array}{c}746.11 \\
(372.34-1277.48)\end{array}$ & $\begin{array}{c}1286.50 \\
(659.5-2509.61)\end{array}$ & $\begin{array}{c}1370.44 \\
(668.48-2431.35)\end{array}$ \\
\hline $\mathrm{Me}(\mathrm{IQR})$ & $\begin{array}{c}55.44 \\
(27.52-88.22)\end{array}$ & $\begin{array}{c}49.71 \\
(17.28-87.65)\end{array}$ & $\begin{array}{c}1160.00 \\
(242.27-2725.84)\end{array}$ & $\begin{array}{c}1340.00 \\
(258.00-2520.81)\end{array}$ & $\begin{array}{c}1407.88 \\
(394.5-4084.88)\end{array}$ & $\begin{array}{c}1614.45 \\
(447.00-3742.45)\end{array}$ \\
\hline
\end{tabular}

$\mathrm{Cl}$ - 95\% confidence limit for mean; $\mathrm{Cr}$ - creatinine corrected; GM - geometric mean; IQR - interquartile range.

\section{By smoking ban level}

The authors also examined biochemical markers by smoking ban level: areas with a complete smoking ban, separated areas, and areas with no smoking ban. It was found that hair nicotine was the highest in areas with no smoking ban $(\mathrm{GM}=2.10 \mathrm{ng} / \mathrm{mg}, \mathrm{Me}=1.67 \mathrm{ng} / \mathrm{mg})$, followed by separated areas $(\mathrm{GM}=1.27 \mathrm{ng} / \mathrm{mg}, \mathrm{Me}=1.55 \mathrm{ng} / \mathrm{mg})$, and areas with a complete smoking ban $(\mathrm{GM}=0.65 \mathrm{ng} / \mathrm{mg}$, $\mathrm{Me}=0.53 \mathrm{ng} / \mathrm{mg}$ ). A similar pattern of results was found for all other biochemical markers. The results were the same when using the bootstrapping method (Table 4).

\section{One-way ANCOVA}

Biomarkers were identified by workplaces. The concentrations of hair nicotine for restaurants and cafés were lower than for karaoke and billiard halls, and Internet cafés, and were statistically significant; however, the concentrations for karaoke and billiard halls, and Internet cafés were not significantly different from one another. The urinary cotinine concentrations for karaoke and billiard halls were significantly higher than for restaurants and cafés, as well as Internet cafés, but the karaoke and billiard hall, and Internet café concentrations were not statistically significant. 
Table 4. Concentrations of hair nicotine, urine cotinine, urine 4-(methylnitrosamino)-1-(3-pyridyl)-1-butanol (NNAL), and dust 4-(methylnitrosamino)-1-(3-pyridyl)-1-butanone (NNK) by type of smoking area, in the study on examining secondhand smoke (SHS) exposure in non-smoking employees, Korea, August-September 2017

\begin{tabular}{|c|c|c|c|c|c|c|}
\hline \multirow{3}{*}{ Substance } & \multicolumn{6}{|c|}{$\begin{array}{l}\text { Participants } \\
(\mathrm{N}=68)\end{array}$} \\
\hline & \multicolumn{2}{|c|}{ complete smoking ban } & \multicolumn{2}{|c|}{ separate smoking room available } & \multicolumn{2}{|c|}{ no smoking ban } \\
\hline & $\mathrm{N}=21$ & iterations $=1000$ & $\mathrm{~N}=29$ & iterations $=1000$ & $\mathrm{~N}=18$ & iterations $=1000$ \\
\hline \multicolumn{7}{|c|}{ Hair nicotine $[\mathrm{ng} / \mathrm{mg}]$} \\
\hline $\mathrm{GM}(95 \% \mathrm{Cl})$ & $\begin{array}{c}0.65 \\
(0.42-0.99)\end{array}$ & $\begin{array}{c}0.66 \\
(0.44-1.04)\end{array}$ & $\begin{array}{c}1.27 \\
(0.79-2.05)\end{array}$ & $\begin{array}{c}1.31 \\
(0.81-2.06)\end{array}$ & $\begin{array}{c}2.10 \\
(1.11-3.95)\end{array}$ & $\begin{array}{c}2.21 \\
(1.13-3.90)\end{array}$ \\
\hline Me (IQR) & $\begin{array}{c}0.53 \\
(0.37-0.73)\end{array}$ & $\begin{array}{c}0.53 \\
(0.37-0.73)\end{array}$ & $\begin{array}{c}1.55 \\
(0.33-2.63)\end{array}$ & $\begin{array}{c}1.55 \\
(0.60-2.57)\end{array}$ & $\begin{array}{c}1.67 \\
(0.72-5.10)\end{array}$ & $\begin{array}{c}1.48 \\
(0.72-5.10)\end{array}$ \\
\hline \multicolumn{7}{|c|}{ Urine cotinine $[\mathrm{ng} / \mathrm{mg}] \mathrm{Cr}$} \\
\hline $\mathrm{GM}(95 \% \mathrm{Cl})$ & $\begin{array}{c}2.90 \\
(1.69-4.96)\end{array}$ & $\begin{array}{c}2.99 \\
(1.68-4.81)\end{array}$ & $\begin{array}{c}6.60 \\
(4.15-10.51)\end{array}$ & $\begin{array}{c}6.69 \\
(4.45-10.69)\end{array}$ & $\begin{array}{c}13.70 \\
(8.71-21.56)\end{array}$ & $\begin{array}{c}14.19 \\
(8.81-21.55)\end{array}$ \\
\hline $\mathrm{Me}(\mathrm{IQR})$ & $\begin{array}{c}5.09 \\
(1.17-7.40)\end{array}$ & $\begin{array}{c}5.09 \\
(1.17-7.40)\end{array}$ & $\begin{array}{c}6.57 \\
(2.77-11.02)\end{array}$ & $\begin{array}{c}6.57 \\
(2.77-11.02)\end{array}$ & $\begin{array}{c}9.96 \\
(6.86-37.29)\end{array}$ & $\begin{array}{c}10.17 \\
(6.86-37.29)\end{array}$ \\
\hline \multicolumn{7}{|c|}{ Urine NNAL [pg/mg] (Cr) } \\
\hline $\mathrm{GM}(95 \% \mathrm{Cl})$ & $\begin{array}{c}1.66 \\
(1.16-2.37)\end{array}$ & $\begin{array}{c}1.69 \\
(1.19-2.37)\end{array}$ & $\begin{array}{c}1.90 \\
(1.53-2.36)\end{array}$ & $\begin{array}{c}1.91 \\
(1.53-2.34)\end{array}$ & $\begin{array}{c}2.90 \\
(1.94-4.33)\end{array}$ & $\begin{array}{c}2.94 \\
(2.03-4.27)\end{array}$ \\
\hline $\mathrm{Me}(\mathrm{IQR})$ & $\begin{array}{c}1.62 \\
(0.86-1.96)\end{array}$ & $\begin{array}{c}1.62 \\
(0.86-1.96)\end{array}$ & $\begin{array}{c}1.70 \\
(1.31-2.94)\end{array}$ & $\begin{array}{c}1.70 \\
(1.31-2.94)\end{array}$ & $\begin{array}{c}2.88 \\
(1.51-4.85)\end{array}$ & $\begin{array}{c}2.84 \\
(1.51-4.85)\end{array}$ \\
\hline \multicolumn{7}{|l|}{ Dust NNK [pg/mg] } \\
\hline $\mathrm{GM}(95 \% \mathrm{Cl})$ & $\begin{array}{c}58.37 \\
(31.17-109.31)\end{array}$ & $\begin{array}{c}60.23 \\
(30.92-112.33)\end{array}$ & $\begin{array}{c}565.42 \\
(284.42-1124.03)\end{array}$ & $\begin{array}{c}605.88 \\
(291.08-1087.48)\end{array}$ & $\begin{array}{c}1470.62 \\
(791.42-2732.71)\end{array}$ & $\begin{array}{c}1530.57 \\
(765.79-2557.18)\end{array}$ \\
\hline $\mathrm{Me}(\mathrm{IQR})$ & $\begin{array}{c}61.18 \\
(37.75-88.8)\end{array}$ & $\begin{array}{c}61.18 \\
(39.55-87.65)\end{array}$ & $\begin{array}{c}710.00 \\
(187.00-2282.5)\end{array}$ & $\begin{array}{c}710.00 \\
(187.00-2282.5)\end{array}$ & $\begin{array}{c}1965 \\
(895.00-3830.00)\end{array}$ & $\begin{array}{c}2240.00 \\
(895.00-3830.00)\end{array}$ \\
\hline
\end{tabular}

Abbreviations as in Table 3.

In the case of urinary NNAL, there was no significant difference between the 3 groups. The dust NNK concentrations in restaurants and cafés were statistically the lowest, and there was no difference between karaoke and billiard halls, and Internet cafés (Figure 1).

Additionally, biomarkers were identified by the smoking ban level. In the case of hair nicotine and urinary cotinine, areas with no smoking ban showed the highest concentrations. Furthermore, the concentrations in those areas were statistically significantly higher than in areas with a complete smoking ban, and concentrations in sep- arated areas were not statistically significant. Moreover, there was no significant difference between the concentrations in areas with a complete smoking ban and in separated areas. Urinary NNAL concentrations were the highest in areas with no smoking ban, followed by separated areas and those with a complete smoking ban; however, there was no significant difference between the 3 groups. The dust NNK concentrations in areas with a complete smoking ban were significantly lower than in separated areas and in those with no smoking ban. The concentrations in separated areas and in areas with 

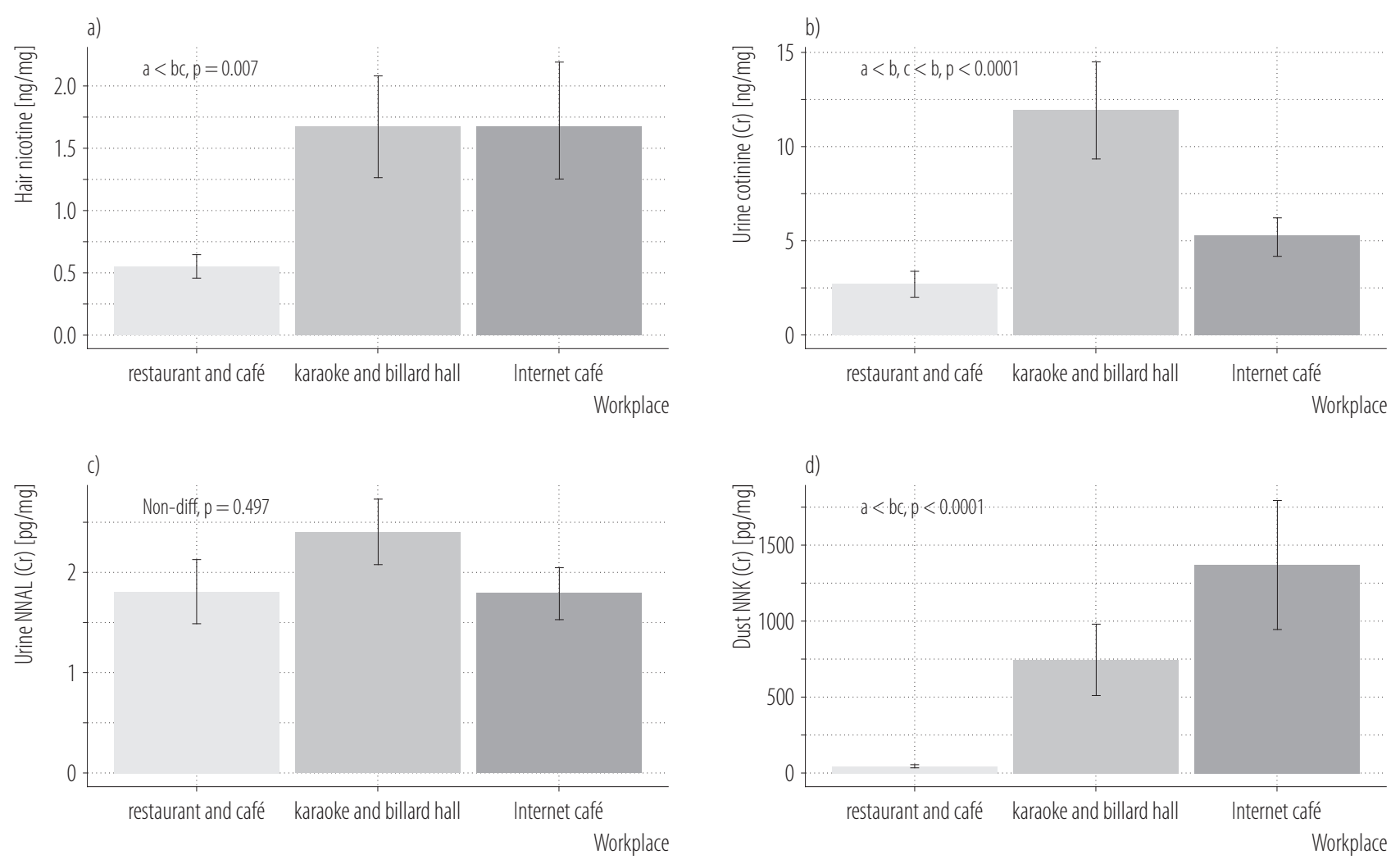

Non-diff - no statistical difference.

Secondhand smoking exposure at home was adjusted. However, it was not statistically significant at the p-value 0.05 level.

Figure 1. Differences in a) hair nicotine, b) urine cotinine, c) urine 4-(methylnitrosamino)-1-(3-pyridyl)-1-butanol (NNAL), and d) dust 4-(methylnitrosamino)-1-(3-pyridyl)-1-butanone (NNK) by workplace (1-way ANCOVA)

no smoking ban were not statistically significantly different (Figure 2).

\section{Two-way ANCOVA}

No significant difference in hair nicotine concentrations was found between restaurants and cafés, and karaoke and billiard halls (Figure 3a). Additionally, urine cotinine concentrations were lower in the restaurants and cafés with a complete ban than in those with separated areas; however, this difference was not significant. Among karaoke and billiard halls, the concentration for urine cotinine was the lowest in areas with a complete ban, followed by separated areas and areas with no smoking ban. In areas with no smoking ban, urine coti- nine was significantly higher than in areas with a complete ban (Figure 3b).

As for urine NNAL, the concentration was lower in restaurants with a complete ban than in those with separate areas, although this difference was not significant. The concentration was the lowest in karaoke and billiard halls with a complete smoking ban, followed by those with separated areas and areas with no smoking ban. The concentration of urine NNAL was also significantly higher in areas with no smoking ban than in areas with a complete ban (Figure 3c).

Finally, dust NNK was lower in restaurants and cafés with a complete ban than in restaurants and cafés with separated areas, but the difference was not significant. The concentration was the lowest in karaoke and billiard halls with 

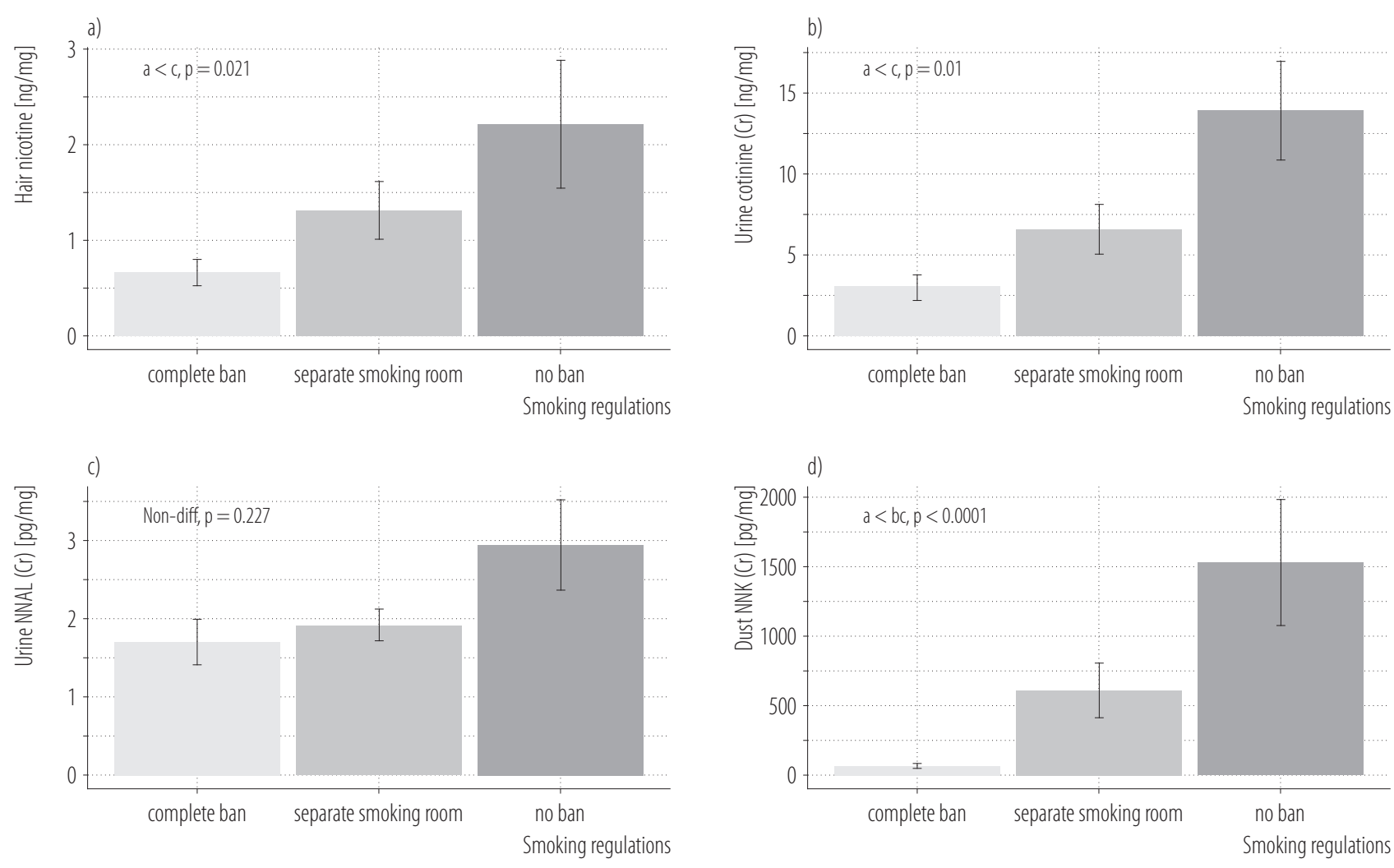

Non-diff - no statistical difference.

Secondhand smoking exposure at home was adjusted. However, it was not statistically significant at the p-value 0.05 level.

Figure 2. Differences in a) hair nicotine, b) urine cotinine, c) urine 4-(methylnitrosamino)-1-(3-pyridyl)-1-butanol (NNAL), and d) dust 4-(methylnitrosamino)-1-(3-pyridyl)-1-butanone (NNK) by smoking ban level (1-way ANCOVA)

separated areas, followed by areas with a complete ban and those with no smoking ban. The concentrations were significantly higher in areas with no smoking ban than in separated areas (Figure 3d). Because all Internet cafés had smoking areas on the premises, the 2-way ANCOVA could not be performed on them.

\section{DISCUSSION}

Smoking in public places (e.g., restaurants, karaoke or billiard halls, and Internet cafés) is one of the oldest tobacco control issues being debated in Korea, largely because facilities can install smoking rooms even when their entire indoor premises are deemed smoke-free. Furthermore, smoking continues to take place in smoke-free zones, lead- ing to exposure to SHS. Nevertheless, SFLs do seem to help prevent SHS exposure, and there have been many studies aiming to provide supporting evidence of this [20,21]. In this study, it was found that while there were notable differences between the biomarkers, all biomarkers had the lowest concentrations in areas with a complete smoking ban, while areas with no smoking ban had the highest concentrations. Separate rooms had higher concentrations than areas with a complete smoking ban, suggesting that no matter what efforts are made to prevent the spread of tobacco smoke, the presence of an indoor smoking room is bound to expose people to SHS [22].

A similar pattern of results was found when performing the analysis by facility: the biomarkers were overall high 

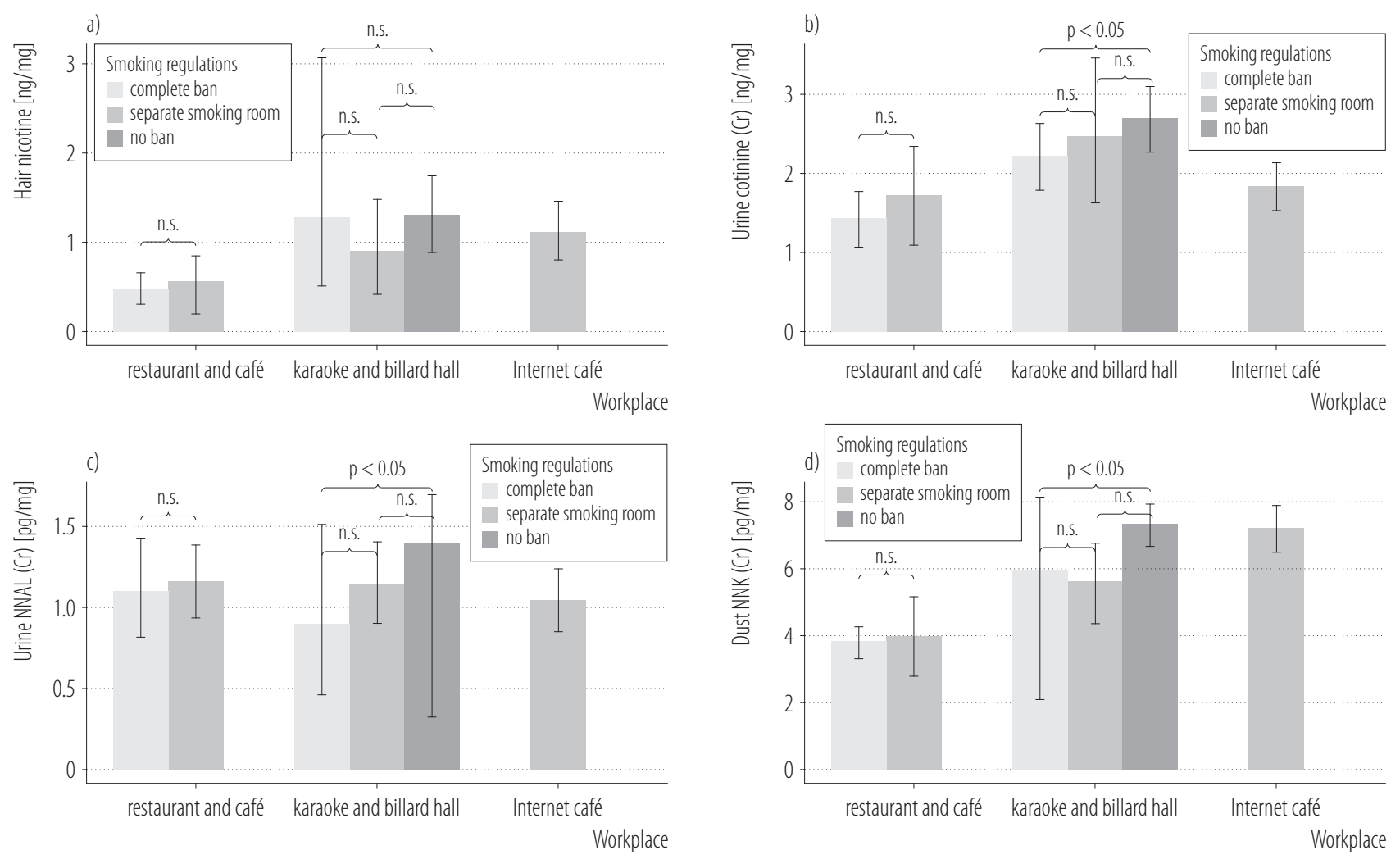

N.s. - not significant.

Secondhand smoking exposure at home was adjusted. However, it was not statistically significant at the p-value 0.05 level.

Figure 3. Differences in a) hair nicotine, b) urine cotinine, c) urine 4-(methylnitrosamino)-1-(3-pyridyl)-1-butanol (NNAL), and d) dust 4-(methylnitrosamino)-1-(3-pyridyl)-1-butanone (NNK) (2-way ANCOVA after 1000 iterations)

among people who worked at karaoke and billiard halls, where smoking was permitted, followed by Internet cafés, and then restaurants and cafés that were smoke-free. The questionnaire supported these findings, with $90.6 \%$, $75.0 \%$, and $35.0 \%$ of workers in karaoke and billiard halls, Internet cafés, and restaurants and cafés, respectively, reporting exposure to SHS. These findings altogether suggest that in South Korea, the designation of a smoke-free zone provides some protection from SHS to workers of restaurants and cafés, as well as Internet cafés, but this is not a complete protection. In particular, the smoke-free sections of Internet cafés do not completely prevent SHS exposure. It was noted that hair nicotine and dust NNK concentrations were higher in Internet cafés where the smoking area was required to be separate, than in karaoke and billiard halls where smoking was allowed freely. The authors suppose that this due to their NNK collection method. The dust NNK was collected by wiping the layer of dust from ventilators. If the ventilators are not cleaned, it is likely that NNK from past smoking events would be present in the dust, even if smoking is not currently taking place. In addition, the presence of urinary cotinine and NNAL can show exposure for $\leq 1$ month, but hair nicotine is an indicator confirming smoking exposure for $>2$ months [16]. In other words, these findings likely reflect the cumulative concentrations of NNK over long periods, rather than current ones. The findings from the 2-way ANCOVA show in detail the degree to which workers are protected from SHS by 

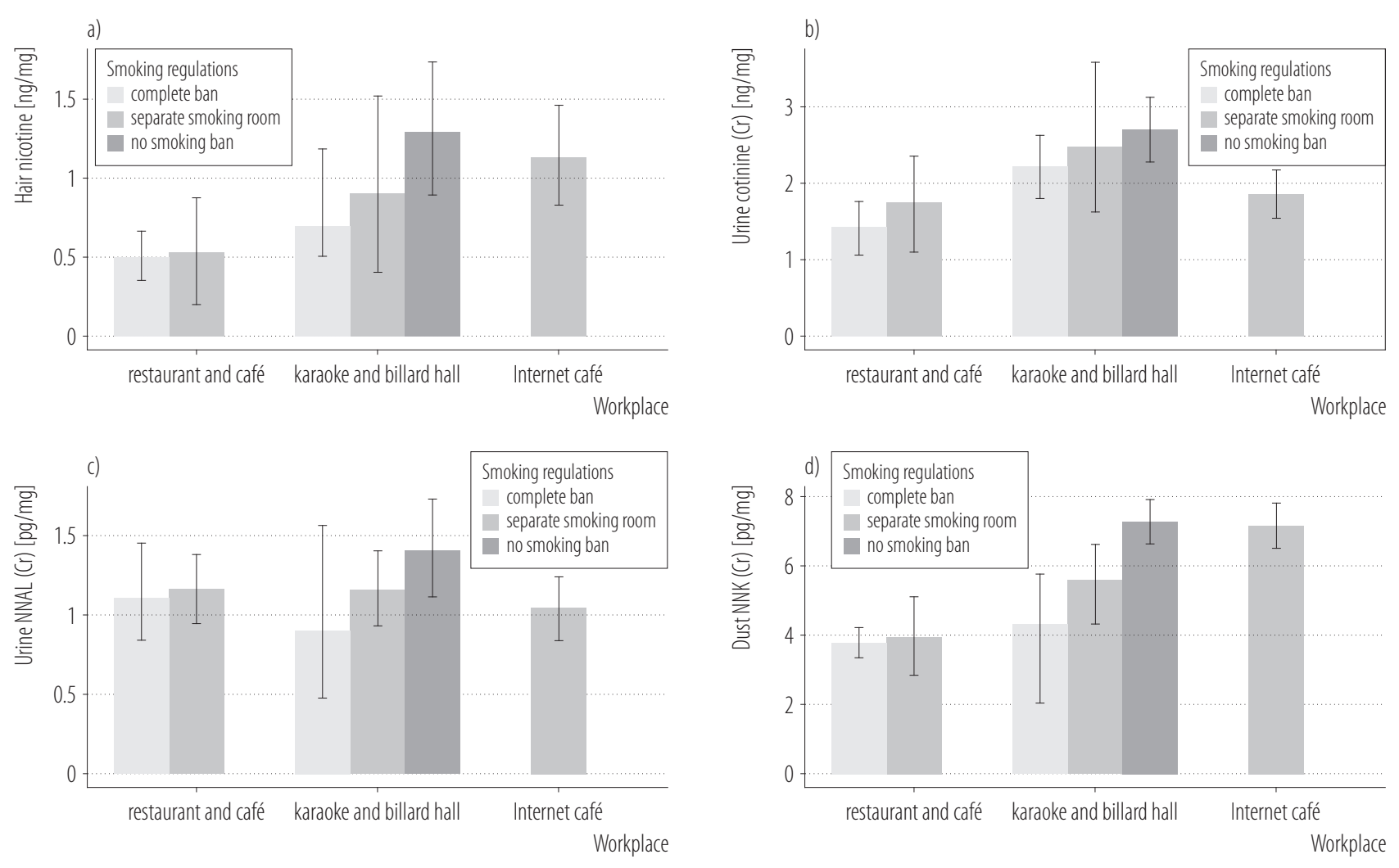

Figure 4. Differences in a) hair nicotine, b) urine cotinine, c) urine 4-(methylnitrosamino)-1-(3-pyridyl)-1-butanol (NNAL), and d) dust 4-(methylnitrosamino)-1-(3-pyridyl)-1-butanone (NNK) (2-way ANCOVA after 1000 iterations) after excluding outlier values

smoke-free zones in different facilities. In restaurants and cafés, no significant difference was observed in any of the markers between areas with a complete smoking ban and separated areas. However, the concentrations of all markers were consistently high in separated areas, implying that workers are still more exposed to SHS when there is a separate smoking room on the premises. Although the short-term urine markers were lower among workers at karaoke and billiards halls, both hair nicotine and dust NNK were higher in these areas than in separated areas. While there may be a number of reasons for these findings, the raw data suggest that some participants had relatively low urine cotinine and NNAL levels but very high hair nicotine levels, and they worked in areas with high NNK levels. In other words, the extreme nicotine and NNK values likely influenced the averages.
Both hair nicotine and dust NNK reflect relatively longer-term exposure than urine markers. The authors actually found, through additional interviews with the participants, that the premises had allowed smoking previously but had imposed a complete ban 3 weeks before the survey. After excluding these facilities, the biomarker concentrations were substantially lower than in areas with a complete smoking ban (Figure 1). Ultimately, these findings imply that exposure to SHS can be prevented if karaoke and billiards halls designate smoke-free zones of their own accord, even when they are not legally required to do so.

Lastly, all Internet cafés involved in the survey had separate smoking rooms, indicating that a high percentage of users were smokers who found it bothersome to leave their game and go outside to smoke. Users of Internet 
cafés pay by time, and some games can proceed for long periods without breaks. If game players were to leave in the middle of a game to go outside to smoke for a prolonged time, it would influence the results of the game. Previous studies conducted in settings similar to these also reported that smoking bans in indoor public places could protect customers and workers from SHS $[4,23]$. Obviously, SFLs can protect SHS, but its effects have not always been consistent.

These results indicate that SFLs do not guarantee a perfect protection against SHS exposure. Additionally, exposure levels tend to vary with the rate of smoking, facilities' willingness to enforce a smoking ban, the surrounding culture, and other social and cultural elements. Restaurants, cafés, and Internet cafés all had similar smoking bans, but there were wide gaps in exposure to SHS, presumably because of the differences in the awareness and culture of smoking in these facilities. These findings imply, on a broader level, that tobacco smoke exposure varies across different countries with SFLs. In the United Kingdom, compliance with SFLs is high, largely owing to the hefty fines and penalties for violating the law, and there are fewer breaches than in other countries.

According to a Eurobarometer survey of EU member states [24], 8.8\% of the participants mentioned witnessing people smoking indoors in restaurants. This figure is an average, however, and the figures by country vary wildly: on the lower end are the United Kingdom and Ireland, at $2.6 \%$ and $3.5 \%$ respectively; on the higher end is Greece (which legally requires restaurants to impose a total ban on smoking), where $77.7 \%$ of the participants reported seeing smokers in restaurants, suggesting a lack of enforcement of SFLs and exceedingly high SHS exposure.

In a previous study measuring air quality as an index of SHS exposure, the researchers concluded that considerable harm could come from SHS exposure in Internet cafés, billiard halls, and pubs [25], drawing attention to the seriousness of SHS in such public places.
Since their inception, SFLs have been fiercely resisted due to concerns for smokers' rights and reduced profits due to the smoking ban $[26,27]$. When certain public places were designated as smoke-free zones in South Korea, the Internet café association and various smokers organizations filed constitutional complaints. However, the courts ultimately did not rule in their favor [28]. Notably, SHS in public places is clearly harmful to users and workers: annually, about 200000 workers die from exposure to SHS in the workplace [21]. Because most of these workers are attempting to earn their livelihood, it is difficult for them to merely avoid exposure to tobacco smoke, not to mention the fact that their exposure is prolonged compared to other individuals (e.g., those exposed in the streets and their customers). Therefore, designation, expansion, and enforcement of smoke-free zones seems essential for preventing workers' exposure to SHS. Arguably, the greatest beneficiaries of such policies would be the workers.

The authors have managed to confirm that the designation of smoke-free zones could help reduce exposure to SHS. Furthermore, enforcement of SFLs and smoking culture might have significant effects on such exposure. Article 8 of the WHO FCTC, which is associated with SHS and the designation of smoke-free zones, is implemented more than any other terms and conditions of the Convention [29]. However, such implementation is more administrative in nature, as viable achievements require enforcement of the relevant SFLs [24]. Governments must, therefore, express their determination to enforce such laws while endeavoring to improve public awareness. For its part, the WHO should not solely focus on the enactment of laws relevant to Article 8. Rather, it might focus more on enforcement and compliance, as this would help monitor the progress of Article 8 in a more accurate manner.

This study has some limitations. Particularly, the findings cannot represent the nation properly because of the use of a small size sample. Furthermore, this result can only 
be applied to workers, not to customers. In addition, only 1 person was surveyed per facility, and the exposure levels and living environments of various workers in the same facility may differ. In addition, the age of the participants working at karaoke and billiard halls was relatively higher, and due to the small sample size, sex and age could not be controlled for. Moreover, there could be a variety of ways by which the participants could have been exposed to SHS.

\section{CONCLUSIONS}

Smoking is prohibited in hospitality facilities to minimize smoking exposure, and SFLs at workplaces are an appropriate measure to protect workers from smoking exposure. However, even if smoking is regulated by law, the degree of exposure depends on the implementation of the law, and the characteristics and culture of the facility. In this study, smoking restrictions for restaurants, cafés, and Internet cafés were at the same level, but those working at the Internet cafés tolerant of smoking were exposed to SHS at higher levels. Finally, exposure to SHS can be effectively prevented when businesses designate smoke-free zones on their premises of their own accord, even when not required by law.

\section{REFERENCES}

1. US Department of Health Human Services. The health consequences of involuntary exposure to tobacco smoke: a report of the Surgeon General. Atlanta, GA: Centers for Disease and Control; 2006.

2. Öberg M, Jaakkola MS, Woodward A, Peruga A, PrüssUstün A. Worldwide burden of disease from exposure to second-hand smoke: a retrospective analysis of data from 192 countries. Lancet. 2011;377(9760):139-46, https://doi. org/10.1016/S0140-6736(10)61388-8.

3. Drope J, Schluger N, Cahn Z, Drope J, Hamill S, Islami F, et al. The Tobacco Atlas. Atlanta: American Cancer Society and Vital Strategies. Atlanta: American Cancer Society; 2018. p. 22.
4. Reijula J, Johnsson T, Kaleva S, Tuomi T, Reijula K. Total prohibition of smoking but not partial restriction effectively reduced exposure to tobacco smoke among restaurant workers in Finland. Int J Occup Med Environ Health. 2013;26(5):68292, https://doi.org/10.2478/s13382-013-0145-8.

5. Frazer K, Callinan JE, McHugh J, van Baarsel S, Clarke A, Doherty K, et al. Legislative smoking bans for reducing harms from secondhand smoke exposure, smoking prevalence and tobacco consumption. Cochrane Database Syst Rev. 2016 Feb 4, https://doi.org/10.1002/14651858.CD005992.pub3.

6. Meyers DG, Neuberger JS, He J. Cardiovascular effect of bans on smoking in public places: a systematic review and meta-analysis. J Am Coll Cardiol. 2009;54(20):1902, https:// doi.org/10.1016/j.jacc.2009.07.022.

7. World Health Organization. The 2018 update,WHO Framework Convention on Tobacco Control. Geneva: The Organization; 2018. p. 8.

8. Gostin LO. Global regulatory strategies for tobacco control. JAMA. 2007;298(17):2057-9, https://doi.org/10.1001/jama.298. 17.2057

9. Minnesota Department of Health [Internet]. St. Paul: The Department; 2019 [cited 2020 Nov 2]. Minnesota Clean Indoor Air Act (MCIAA). Available from: https://www.health.state. mn.us/communities/environment/air/mciaa/index.html.

10. American Nonsmokers' Rights Foundation. Overview List Number of Smokefree and Other Tobacco-Related Laws [Internet]. The Foundation; 2018-2020 [cited 2020 Mar 15]. Available from: http://no-smoke.org/wp-content/uploads/pdf/ mediaordlist.pdf.

11. [Law on the introduction of a smoking ban in federal facilities and public transport. Federal Non-Smoking Protection Act. Federal Law Gazette 2007, part I, No. 35 (BGBl. I S. 1595)]. German.

12. Third of pubs 'not ready for ban' [Internet]. BBC News; 2007 March 2 [cited 2020 Mar 15]. Available from: http://news. bbc.co.uk/2/hi/uk_news/wales/6410215.stm.

13. Nam I-S. Smoking Ban Snuffing Out South Korea's Internet Cafes. Wall Street J. 2014 Sep 1. 
14. Kim J. "Is pc room a smoking zone?" 8 out of 10 smokers caught on PC room [Internet]. EDAILY; 2014 April 9 [cited 2020 Nov 2]. Available from: https://www.edaily.co.kr/news/read?ne wsId $=02118886606054480 \&$ mediaCodeNo $=257$. Korean.

15. World Health Organization. WHO report on the global tobacco epidemic, 2015: raising taxes on tobacco. Geneva: The Organization; 2015. p. 56-61.

16. Avila-Tang E, Al-Delaimy WK, Ashley DL, Benowitz N, Bernert JT, Kim S, et al. Assessing secondhand smoke using biological markers. Tob Control. 2013;22(3):164-71, https:// doi.org/10.1136/tobaccocontrol-2011-050298.

17. Changyong F, Hongyue W, Naiji L, Tian C, Hua H, Ying L, et al. Log-transformation and its implications for data analysis. Shanghai Arch Psychiatry. 2014;26(2):105-9, https://doi. org/10.3969/j.issn.1002-0829.2014.02.009.

18. Linden A, Adams JL, Roberts N. Evaluating disease management program effectiveness. Dis Manage Health Outcomes. 2005;13(3):159-67, https://doi.org/10.2165/00115677200513030-00002.

19. Akins RB, Tolson H, Cole BR. Stability of response characteristics of a Delphi panel: application of bootstrap data expansion. BMC Med Res Methodol. 2005;5:37, https://doi. org/10.1186/1471-2288-5-37.

20. Park J-H, Lee C-K, Kim S-Y, Suh C, Kim K-H, Kim J-H, et al. Decline in non-smoking workers' urine cotinine levels after increased smoking regulation in Korea. Ann Occup Environ Med. 2015;27:17, https://doi.org/10.1186/s40557-015-0066-z.

21. Global Smokefree Partnership [Internet]. Geneva: Framework Convention Alliance; 2018 [cited 2020 Nov 2]. Global Smokefree Partnership and National Committee for Smoking Prevention. Key facts on Smoking, Smokefree and the "Spanish Model". Available from: https:/www.fctc.org/wp-content/ uploads/2010/09/Spain_smokefree_key_facts.pdf.

22. Centers for Disease Control and Prevention [Internet]. Atlanta: The Centers; 2020 [cited 2020 Nov 2]. Ventilation
Does Not Effectively Protect Nonsmokers from Secondhand Smoke. Available from: https://www.cdc.gov/tobacco/ data_statistics/fact_sheets/secondhand_smoke/protection/ ventilation/index.htm.

23. Sansone G, Fong GT, Meng G, Craig LV, Xu SS, Quah AC, et al. Secondhand Smoke Exposure in Public Places and Support for Smoke-Free Laws in Japan: Findings from the 2018 ITC Japan Survey. Int J Environ Res Public Health. 2020;17(3):979, https://doi.org/10.3390/ijerph17030979.

24. Attitudes of Europeans towards tobacco and electronic cigarettes. Report. Special Eurobarometer 458. Brussels: European Commission, Directorate-General for Communication; 2017. Report No. EW-04-15-308-EN-N. p. 77, 141, https://doi. $\operatorname{org} / 10.2875 / 670456$.

25. Lee JH, Park D, Ha K. Evaluation of Indoor ETS Exposure Levels in Pubs, PC Game Rooms, and Billiards Halls around a University Campus using PM2.5 Concentrations. J Korean Soc Occup Environ Hyg. 2016;26(4):414-7, https://doi. org/10.15269/JKSOEH.2016.26.4.411.

26. Kohler S, Minkner P. Smoke-free laws and direct democracy initiatives on smoking bans in Germany: a systematic review and quantitative assessment. Int J Environ Res Public Health. 2014;11(1):685-700, https://doi.org/10.3390/ijerph11 0100685.

27. Action on Smoking and Health [Internet]. London: The Ash; 2019 [cited Jul 17, 2020]. Electon 2005: Parties Disagree Over Smokefree Law. Available from: https://ash.org. uk/media-and-news/press-releases-media-and-news/election-2005-parties-disagree-over-smokefree-law.

28. The Korea Times [Internet]. Hyun-woo N. Internet cafe owners cry foul over smoking ban. 2013 Jul 23. [cited 2019 Dec 3]. Available from: http://koreatimes.co.kr/www/news/ nation/2013/08/113_137965.html.

29. World Health Organization. The 2016 update. Global tuberculosis report 2016. Geneva: The Organization; 2016. p. 11-3.

This work is available in Open Access model and licensed under a Creative Commons Attribution-NonCommercial 3.0 Poland License - http://creativecommons.org/ licenses/by-nc/3.0/pl/deed.en. 